\title{
BADIUS ASCENSIUS Y LAS DECLAMATIONES MAIORES 1, 4, 5 Y 6
}

\author{
BADIUS ASCENSIUS AND MAIORES DECLAMATIONS 1, 4, 5 Y 6
}

Ma ÁNGELES ROBLES SÁNCHEZ ${ }^{1}$

I.E.S Villa de Abarán (Murcia-España)

\begin{abstract}
Resumen
El presente artículo detalla determinados pasajes, apostillados por el humanista. Concretamente me centraré en las recreaciones mitológicas que incorpora en sus escolios, en el análisis de los ejemplos que arguye para ilustrar sus explicaciones y su contextualización en la ideología renacentista. Finalmente aludiré a las aportaciones que brinda como renovado gramático.
\end{abstract}

Palabras clave: Badius Ascensius, Declamationes, comentario.

\begin{abstract}
My work focuses on detailing certain pasages, which annotates the humanist. I will focus specifically on the mythological recreations which he incorporates in his notes, on the analysis of the examples wich he argues to illustrate their explanations and his contextualization in Renaissance ideology. Finally I shall refer to the contributions than he provided as a grammarian renewed.
\end{abstract}

Key words: Badius Ascensius, Declamationes, commentaries.

Los comentarios de Badius Ascensius² (1462-1535) ofrecen, más allá de su valor filológico, el carácter de escrito de un periodo, de momento de una cultura, este aspecto es el que va a ser destacado en el artículo. Hay que insistir en la importancia de llegar a comprender cómo y con qué actitud leían entonces las obras de los autores romanos y griegos. La exégesis a las Declamationes Maiores nos deja entrever no solo una preceptiva literaria, sino que atestiguan el sistema ideológico que corresponde al período en que

\footnotetext{
${ }^{1}$ Murcia. Correo-e: mangelesroblessanchez@gmail.com. Recibido: 29-01-2017. Aceptado: 14-11-2017.

${ }^{2}$ Jodocus Badius Ascensius (1462-1535) fue impresor en Francia, Estudió Gramática y Literatura en Lyon; trabajó como corrector y consejero literario junto a los primeros editores de la ciudad de 1492 a 1498. Posteriormente, en París funda, hacia el año 1500, una imprenta de la que saldrán numerosas ediciones valiosas. Escribió libros de gramática, tratados morales y poesía latina. Publica él mismo algunos escritos, entre otros Navicula stultarum mulierum en el año 1500. Annotationes doctorum viroru[m] in grammaticos, oratores, poetas, philosophos, theologos $\mathcal{E}$ leges (1511). Elabora varias ediciones en las que aparecen las Declamationes: la Ascensiana II de 1519 incluye las Institutiones Oratoriae con las XIX Declamationes. La Ascensiana IV de 1528 contiene las Institutiones Oratoriae y le fueron añadidas las XIX Declamationes con notas suyas. También, comentó a Virgilio: Opera Virgiliana cum decem commentis dicte et familiariter exposita (1529). (Renouard, 1908), (White, 2013).
} 
se elaboraron ${ }^{3}$. Decía Ferdinand de Saussure ${ }^{4}$ que la antropología de la lengua esta intrínsecamente relacionada con los grupos sociales. Los valores connotativos de las palabras son compartidos por todos los miembros de una comunidad lingüística, fruto de la utilización del mismo código. El tipo de comentario que nuestro exégeta realizó sigue los principios pedagógicos que Erasmo propone en su Liber de ratione studii ac legendi interpretandique auctores (1511). En esta obra describe los pasos que debe dar el humanista ante sus alumnos. Estas consideraciones teóricas que plantea las llevó a cabo en sus trabajos, como advierten Chomarat ${ }^{5}$ y Merino $^{6}$. La primera pauta es la captatio benevolentiae. Seguidamente, se elaborará el comentario con anotaciones de índole estilística (arcaísmos, neologismos, helenismos...), gramatical (derivaciones, composiciones), retórica (figuras y tropos) y textual (corrección de pasajes corruptos). Antes de concluir la explicación con una enseñanza moral, puede servirse de su erudición para establecer paralelos con otros autores, señalando alusiones y semejanzas. Estos principios son los que estructuran el comentario de Ascensius en su edición ${ }^{7}$. El erudito realiza aclaraciones acerca del contenido, utiliza, como recurso, los ejemplos de otros autores; también, aborda en sus glosas cuestiones léxicas, gramaticales y referentes a la crítica textual.

En este trabajo nos vamos a centrar en algunas anotaciones, arrojando luz a lo que deja entrever y encomienda al lector que interprete ${ }^{8}$. Concretamente, me centraré en las Declamationes 1, 4, 5 y 6, en tres puntos':

1. Las recreaciones mitológicas que incorpora en sus escolios. Igualmente, aludiré al alcance de algunos mitos en otras obras literarias como una tendencia de su tiempo.

2. Análisis de los ejemplos, que arguye, para ilustrar sus explicaciones y su contextualización en la ideología renacentista.

3. Las aportaciones que brinda como renovado gramático.

\footnotetext{
${ }^{3}$ San Jerónimo y Servio consideraban que el autor de Las Declamationes Maiores y Minores era el rétor de Calahorra: Hieron. Epist. 14, 3 y Serv. A. 3, 661. Los autores actuales se dividen. M. Winterbotton y G. Kennedy consideran que estas obras son del rétor riojano. Si Quintiliano no es el autor de estas dos obras, debe de ser de un contemporáneo, perteneciente a su escuela. El estilo de las Declamationes Minores y Maiores siguen en la línea del estilo de la Institutio. (Winterbottom, 1984: 15), (Kennedy, 1972: 321-322). En contraposición, tenemos la opinión de M. von Albrecht quien afirma que las 19 Declamationes no son auténticas. (Albrecht, 1999: 1146).

${ }^{4}$ (Saussure, 1945).

${ }^{5}$ (Chomarat, 1981: 281-299).

${ }^{6}$ (Merino, 1992: 182-185).

${ }^{7}$ Sobre un estudio más profundo acerca del tipo de comentario que realiza Badius en su edición de las Declamationes véase: (Robles, 2014:1207-1220). En este artículo se analizan los diferentes tipos de comentarios que el humanista aborda, específicamente, en la práctica declamatoria primera.

${ }^{8}$ (González Vega, 2003: 155-167).

${ }^{9}$ A. Weische asegura que la influencia directa en la producción de sus coetáneos fue más bien escasa. Ahora bien, durante el humanismo renacentista, la obra del retórico y pedagogo hispanorromano obtiene una repercusión considerable. (Weische, 1978: 147-166), (Fernández López, 1999: 913-924).
} 


\section{LAS RECREACIONES MITOLÓGICAS}

Los autores del siglo XVI buscaron en la mitología los aspectos relacionables con las situaciones representadas en sus escritos, por consiguiente, convirtieron en tópicos muchos episodios mitológicos. El erudito pone en escena a personajes mitológicos con el fin de dilucidar determinados episodios de las Declamationes ${ }^{10}$. Convertirá en símbolo de avaricia el mito de Polidoro (Quint. Decl. 1, 13). El de Tiestes y Orestes (Quint. Decl. 4, 16), que se narran en el mismo contexto, sugieren la maldad del ser humano; finalmente, el de Medea (Quint. Decl. 6, 2) describe, a lo vivo, un modelo de comportamiento.

\subsection{El mito de Polidoro}

El rétor, originario de Calahorra, en la Declamatio ${ }^{11} 1,13$ describe la manera de proceder de una noverca, al hilo de la defensa del muchacho ciego, acusado por la madrastra de ser un parricida ${ }^{12}$. Quintiliano habla de la avaricia de la madrastra como móvil del asesinato. El escoliasta ${ }^{13}$ ahonda en los sentimientos humanos, cuestión muy debatida en este período, al ser el hombre el centro del universo. Apunta unos hexámetros de la Eneida ${ }^{14}$ (Verg. A. 3, 49-57); el épico mantuano narra la llegada de Eneas a Tracia, tras partir de Troya, para fundar su nueva morada. Mientras recogía ramas para adornar el altar destinado al sacrificio, observó que uno de los arbustos destilaba gotas de sangre. $\mathrm{Al}$ instante, se oyó la voz de Polidoro desde el más allá que contaba su triste destino (Verg. A. 3, 22-68). El hijo de Príamo y Hécuba había sido enviado por su seguridad, durante la guerra de Troya, junto a Poliméstor, rey del Queroneso tracio, con una gran cantidad de oro. Mientras Troya resistió, se respetó su vida, pero cuando Troya cayó, muertos Héctor y Príamo, fue asesinado por el traidor

\footnotetext{
${ }^{10}$ Sobre las prácticas declamatorias, su temática, alcance, personajes, recursos literarios, puesta en escena y desarrollo: (Bornecque, 1902), (Deratani, 1929: 184-189), (Helm, 1955: 87-98), (Jones, 1998: 568569), (Felice, 2001: 53-54), (Hömke, 2002), (Robles, 2009: 204-217).

${ }^{11}$ Tuitus sum adulescentis miserrimi causam. Nunc inspicere volo, quanto certioribus argumentis noverca teneatur. Transeo illum vulgarem et omnibus notum de conparatione personarum locum. (Quint. Decl. 1, 13).

${ }^{12}$ En esta Declamatio interviene un padre y un hijo ciego, a quien había nombrado como heredero; el progenitor le dio una nueva madre al niño y puso al joven en un lugar apartado de la casa. El padre, durante la noche, mientras dormía con su esposa en la habitación, fue asesinado y encontrado, al día siguiente, con la espada de su hijo clavada en la herida, al tiempo que la pared estaba manchada de sangre por marcas de los dedos en la habitación de su hijo. El hijo ciego y la madrastra se acusan mutuamente.

${ }^{13}$ Haec est declamationis huius pars secunda, in qua transfertur crimen ab adolescente in novercam. Utitur autem in pricipio tribus locis communibus, duobus per occupationem, et tertio per applicationem...Tertius sumitur ab avaritia quae nefandae proditionis, et diri homicidii saepe causa fuit. Unde tertio Aeneidos cum Priamus Polydorum filium natu minimum apud Polymestora regem Thraciae cum multa vi auri sub bellum troianum deposuisset, Polymestor capta Troia, Polydorum obtruncat, et auro vi potitur: unde merito exclamat poeta: quid non mortalia pectora cogis Auri sacra fames...(Badius Ascensius, 1528: fol. vi R).

${ }^{14}$ Hunc Polydorum auri quondam si cum pondere magno/infelix Priamus furtim mandarat alendum/Threicio regi, cum iam diffideret armis/Dardaniae cingique urbem obsidione videret./ille, ut opes fractae Teucrum et Fortuna recessit,/res Agamemnonias victriciaque arma secutus/fas omne abrumpit: Polydorum obtruncat, et auro/ ui potitur. quid non mortalia pectora cogis,/auri sacra fames!... (Verg. A. 3,49-57).
} 
Poliméstor, deseoso de quedarse con el oro. Finalmente, su cadáver fue arrojado al mar. El poeta mantuano ${ }^{15}$ no hace más que añadir otro eslabón a la cadena de la tradición que perpetúa y recrea indefinidamente los tópicos folclóricos universales. En cada época y en cada cultura, se modela la versión recibida y se transmite a la siguiente generación, incorporándole variantes y adornándola, según el gusto dominante o según otras circunstancias particulares.

Respecto al manejo como recurso literario de un espectro ${ }^{16}$, hay que decir que la figura del fantasma ${ }^{17}$ no ha sido especialmente frecuente en el teatro griego ${ }^{18}$. De este recurso literario se sirve el elegíaco, originario de Sulmona, en la Heroida XIII donde Laodamía sueña con su esposo Protesilao, que se le aparece con aspecto pálido y triste ${ }^{19}$. En etapas posteriores, este motivo, que reside en la tradición popular, alcanza una distribución auténticamente universal al encarnarse en el denominado cuento del hueso cantor ${ }^{20}$. Dante recrea esta situación en el canto decimotercero del infierno ${ }^{21}$. Boccaccio pone de manifiesto esta historia en el relato IV, 5 del Decamerón ${ }^{22}$. El

\begin{abstract}
${ }^{15}$ (Cristóbal, 1999: 27-44).
${ }^{16}$ Sófocles y Eurípides justifican la vuelta a la vida como fantasma, si se ha muerto prematuramente, ăopoì. Las otras dos condiciones posibles son encontrarse äTaфol, como hace Homero con Patroclo en la Ilíada - o morir violentamente, ßıаıoӨávatol, siguiendo a Platón Leyes VIII 865 d-e. Estas tres circunstancias que estudia Stramaglia en los fantasmas helenísticos están reunidas en Polidoro, pues, a la falta de sepultura une la muerte prematura y violenta. (Stramaglia, 1999: 9-10).
\end{abstract}

${ }^{17}$ Tres casos conservamos donde se pone en escena a personajes del Hades: Darío en Los Persas de Esquilo, Clitemestra en las Euménides de Esquilo y Polidoro en la Hécuba de Eurípides. Intervienen una sola vez en el drama y desaparecen después de su parlamento, que es breve. Cuando aparecen, aclaran el motivo de su presencia y la vinculación que tienen con el Hades, es decir, que han muerto y vuelven al más allá. (Aguirre, 2006: 107-120).

18 (Hernán- Pérez, 2009: 31-47).

19 aucupor in lecto mendaces caelibe somnos;/ dum careo veris gaudia falsa iuvant./Sed tua cur nobis pallens occurrit imago? (Ov. Ep. 12, 107-109).

${ }^{20}$ Es un cuento muy frecuente en numerosísimas tradiciones y también se halla documentado en el ámbito hispánico. La trama esencial es la muerte de un niño a manos de sus hermanos, que lo entierran en un lugar remoto. No se vuelve a saber nada más del joven hasta que el crimen sale a la luz, cuando un pastor pasa por ese lugar, encuentra un huesecillo y fabrica con él un instrumento musical: cada vez que lo toca, suena una canción que delata el crimen y descubre a los asesinos. En otras versiones, es una planta que revela el cruel asesinato. (Propp, 1998: 150), (Genette, 1970: 193-208).

${ }^{21}$ En el pasaje del arbusto que sangra vv. 31-54, el protagonista toma un rama de un gran arbusto y es sorprendido por un grito "¿Por qué me quiebras?" Seguido de sangre marrón que sale del punto de quiebre. De nuevo llegan palabras de la planta “¿Por qué me desgarras? / ¿No tiene tu espíritu piedad alguna?/Hombres fuimos y ahora nos han hecho plantas" (vv. 35-37). Entonces Dante, asustado, deja inmediatamente la rama. (Cristóbal, 1999: 27-44).

${ }^{22}$ Ahora bien, aunque el conjunto del relato sea creación exclusiva y fruto del ingenio del humanista italiano, en él se entrelazan una serie de temas y de tópicos folclóricos que enriquecen el argumento y modelan la historia, hasta perfilarla tal y como la conocemos. En este relato, el elemento folclórico es la aparición del fantasma de Lorenzo a la desconsolada Lisabetta, como una huella de un conjunto de tópicos folclóricos ampliamente documentado en diferentes tradiciones universales. En ellos se narra el regreso cordial, sin ninguna intención dañina, de ciertos difuntos que se aparecen a diferentes deudos y familiares con el objetivo de consolarlos, cuidarlos o de cumplir alguna obligación contraída en vida. (Garroso, 2010: 163-177). 
personaje del espectro es determinante en la obra de Hamlet de William Shakespeare a pesar de sus breves apariciones ${ }^{23}$.

\subsection{El mito de Tiestes}

El mito del Atrida ${ }^{24}$ y el de Orestes son narrados por nuestro glosador ${ }^{25}$ en el mismo marco. Estos personajes encarnan una maldición divina. Se ubican en la paráfrasis a la Declamatio 4, 16, denominada Mathematicus ${ }^{26}$. El protagonista es vaticinado como futuro parricida por un matemático. Por este motivo, Quintiliano ${ }^{27}$ se lamenta, preguntándose qué elementos se confabularon en el día de su nacimiento o qué espíritu maligno se reencarnó en él para merecer este aciago destino. El orador riojano menciona la transgresión del orden establecido por un hecho criminal. No plantea de manera directa el mito de Tiestes en el enunciado: fortassis in me renatus sit aliquis ex illis, quorum scelere violatus dies mundum subito mutavit. (Quint. Decl. 4, 16).

\footnotetext{
${ }^{23}$ El espectro inicia su intervención en el acto I, escena I, señalando el poco tiempo que le queda para entregarse a las "llamas de azufre" y el deseo de venganza que debe satisfacer Hamlet. La próxima y última vez que advertiremos la aparición breve de este espectro será en la escena IV del acto III, cuando Hamlet discute con su madre.

${ }^{24}$ Los dos hermanos Atreo y Tiestes, instigados por su madre, mataron a Crisipo, un hermanastro suyo. Pélope, al enterarse, los maldijo y desterró. Ambos se refugiaron en Micenas, en la corte de Esténelo. Cuando murió el rey, ambos se enfrentaron por el trono. Atreo sacrificó un carnero de su rebaño que tenía el vellón de oro, pero rellenó y guardó orgulloso la piel del animal. Tiestes, celoso, convenció a la mujer de su hermano de que sería su amante, si le entregaba el vellocino de oro. Después del robo, propuso a Atreo que sería rey aquel que poseyera un vellón de oro. Él aceptó, sin sospechar nada, y perdió sus derechos. Una última prueba tuvo que ver con la marcha del sol: si el astro se pusiera por el este, sería Atreo el soberano. Zeus cambió el curso solar, favoreciéndole así. Fue coronado y Tiestes desterrado; después de cierto tiempo, descubrió la infidelidad de su esposa, arrojó a su esposa al mar y, fingiendo perdonar a su hermano, lo invitó a un banquete. Allí, como ya había ocurrido con su abuelo Tántalo, fueron despedazados y guisados los propios hijos de su hermano. Al final de la comida, Tiestes descubrió con horror las cabezas de sus hijos. Vomitando, maldijo para siempre a los descendientes de su hermano.
}

${ }^{25}$ Si verum est quod dicunt Pythagorici animas reddi rursus aliis corporibus post vetusta saecula, et innumerabiles annos (id autem verum non est, sed coram illis iudicibus, ut hic dicitur permissa si particula, non male dicitur.) Fortassis aliquis ex illis quorum scelere dies, id est, sol violatus ut scelere Thiestae, mutavit subito mundum in tenebras: quos fugientes per maria et terras faces furiales (ut de Orestae matricida tragoediae canunt, et Maro [in libro] Aene[idos]iiii [=Verg. A. 4, 471-472] terror dearum aut dirarum ultricum (ut [in libro]aene[idos] iiii [=Verg. A. 4, 473] ultricesque sedent in limine dirae) agitavit, id est, persecutus est; aliquis dico ex illis, est renatus in me. (Badius Ascensius, 1528: fol. R. xxvi-xxvii A).

${ }^{26}$ Un hombre consulta a un matemático acerca del destino del hijo que va a nacer. El matemático le responde que va a tener un hijo fuerte pero que mataría a su padre. Llegada la adolescencia, su padre, impasible ante el futuro que se le había augurado, mandó a su hijo a la guerra y lo dotó de todo el armamento. El muchacho se hizo muy fuerte en la batalla y cuando regresó, ante el temor de llevar a cabo lo que se le había predestinado, decide suicidarse. Manifiesta su temor de matar a su padre, mientras muere por ello, invoca a sus conciudadanos que le ayuden, para evitar que en esos últimos instantes, mientras le quede un aliento de vida, asesine a su padre.

${ }^{27}$ Credo mehercules in illum natalem monstri mei diem iratorum numinum conspirasse violentiam sedemque prodigiosi spiritus conlato pariter igne pressisse. si verum est post vetusta saecula et innumerabiles annos reddi rursus aliis corporibus animas, fortassis in me renatus sit aliquis ex illis, quorum scelere violatus dies mundum subito mutavit, quos <per> maria terrasque fugientes furiales faces et ultricum dearum terror agitavit.(Quint. Decl. 4, 16). 
Es Badius ${ }^{28}$ quien lo nombra, quizás, influido por el autor de Las Declamationes donde apunta a la saga de Tántalo, a Orestes en la subordinada relativa: quos <per> maria terrasque fugientes furiales faces et ultricum dearum terror agitavit. (Quint. Decl. 4, 16). El nombre de Tiestes, citado por nuestro interpres, en nuestra opinión, simboliza la idea del banquete sacrificial. La carne de la víctima servida a la mesa, ha sido representada investida de diferentes significados. En el siglo I d.C. Séneca ${ }^{29}$ toma como base este mito y escribe una tragedia homónima.

En la dramaturgia universal, podemos rastrear innumerables narraciones en las que la carne de la víctima se convierte en ambrosía del asesino ${ }^{30}$. La figura del antropófago involuntario aparece, una y otra vez, en la dramaturgia occidental, encarnando un tabú: el canibalismo.

\subsection{El mito de Orestes}

El autor de Las Declamationes da a entender el mito de Orestes en el siguiente texto: quos <per> maria terrasque fugientes furiales faces et ultricum dearum terror agitavit. (Quint. Decl. 4, 16). El acusativo furiales faces pertenece al campo semántico de las Furiae o Dirae ${ }^{31}$. Con el sintagma ultricum dearum terror se indica el efecto que las Euménides producían, no obstante, las ultrices deae, objeto del miedo, no aparecen numeradas ${ }^{32}$. El erudito de los Países Bajos examina en sus notas estos vocablos y los amplía, plantea la dualidad de una persona, con dos caras: es verdugo y víctima ${ }^{33}$. En la primera faceta se resalta la condición de homicida, temática que recogen, según explicita, los dramaturgos. No incorpora el nombre de ninguna tragedia, quizás, porque en la mente de todos estaban: Esquilo, Sófocles, Eurípides y su homónima composición literaria Electra.

\footnotetext{
${ }^{28}$ Véase nota 24.

${ }^{29}$ Séneca relata el convite siniestro que Atreo le obsequia a su hermano Tiestes, dándole a comer sus propios hijos, como represalia por haber cometido adulterio con su mujer y haber robado de sus establos el cordero de oro, signo de realeza. El mismo Atreo asegura que ofrecerá un macabro manjar como revancha. Tiestes come a sus hijos sin saberlo. Aquí también el festín es una larga escena donde se describen los gustos de la boca y la pesadez de la comida.

${ }^{30}$ La tragedia Progne del veneciano Gregorio Correr (1409-1464), preparada en Mantua en 1427, está compuesta teniendo en cuenta la estructura dramática del Tiestes de Séneca. (Herrero y Morales, 2008: 156-157), (Tola, 2010: 117-130). También, en su tragedia de sangre Tito Andrónico, Shakespeare ofrenda al espectador un espectáculo perverso que tiene puntos en contacto con el Tiestes de Séneca y el aludido relato de Ovidio. En este caso, se trata de las viandas que el protagonista sirve a Támora, reina de los godos. El plato principal son sus hijos cocinados en un pastel, como resarcimiento por la violación y mutilación de su hija Lavinia. (Ingberg, 2004: 207).

${ }^{31}$ Estas espantosas deidades, vengadoras, son caracterizadas con serpientes enroscadas en sus cabellos, portando látigos y antorchas, y con sangre manando de sus ojos en lugar de lágrimas.

${ }^{32}$ Virgilio nombra tres: Alecto (Verg. A. 7, 563), Megera (Verg. A. 12, 846) y Tisífone (Verg. A. 6, 555).

${ }^{33}$...quos fugientes per maria et terras faces furiales (ut de Orestae matricida tragoediae canunt, et Maro [in libro] Aene[idos] iiii [=Verg. A. 4, 471-472] terror dearum aut dirarum ultricum (ut [in libro]aene[idos] iiii [=Verg. A. 4, 473] ultricesque sedent in limine dirae) agitavit, id est, persecutus est; aliquis dico ex illis, est renatus in me. (Badius, 1528: fol. xxvii A).
} 
Por otro lado, en el papel de víctima, se destaca su condición de alma maldita, cuando subraya el pasaje de Virgilio ${ }^{34}$ (Verg. A. 4, 471-472). En él se habla de la presencia de las Erinas sentadas en el umbral del infierno (Verg. A. 4, 473). Aclaro que las

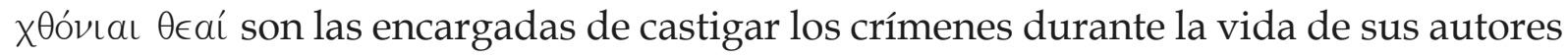
materiales, y no más tarde. No obstante, siendo su campo de acción ilimitado, si el autor del crimen muere lo perseguirán hasta el inframundo, como sucede en este texto del mantuano. Son justas pero sin piedad, ningún rezo ni sacrificio puede conmoverlas ni impedir que lleven a cabo su tarea. Rechazan las circunstancias atenuantes y castigan todas las ofensas contra la sociedad y la naturaleza, como el perjurio, la violación de los ritos de hospitalidad y, sobre todo, los crímenes o asesinatos contra la familia.

En épocas antiguas, se creía que los seres humanos no podían ni debían castigar tan horribles crímenes. Las Erinas ${ }^{35}$ eran las encargadas de perseguir al desterrado asesino del fallecido en venganza. Lo hostigaban hasta hacerle enloquecer. La tortura solo cesaba si el criminal encontraba a alguien que le purificase de sus crímenes. En el anverso de esto, se encuentra la concepción fundamental del espíritu helénico: el orden del mundo debe ser protegido contra las fuerzas anárquicas. El asesinato es una contaminación del orden religioso que pone en peligro la estabilidad del grupo social en el que se ha cometido.

\subsection{El mito de Medea}

Finalmente, el disertador rememora los actos de la hija de Eetes enmarcados en sus observaciones a la Declamatio 6 titulada: Corporis proiecti, ipsa est anus caecae. Nuestro glosador menciona a la Maga de la Cólquide para arrojar luz en la sentencia que maneja Quintiliano: non est filii mei noverca, sed mater (Quint. Decl. 6, 2). El orador pone en escena al padre del muchacho muerto. Él recrimina el comportamiento de su esposa, pues, ella no quiere otorgar los ritos funerarios oportunos al hijo, por lo tanto, la tilda de noverca.

A tenor de lo expuesto, nuestro interpres amplía este lugar, diciendo que va contra la natura que una madre tenga esos sentimientos hacia un hijo ${ }^{36}$. Sin embargo, afirma que uno pueda ser inundado por un saevus amor como le ocurrió a Medea en las Bucólicas del mantuano ${ }^{37}$.

\footnotetext{
${ }^{34}$ Aut Agamemnonius scaenis agitatus Orestes,/armatam facibus matrem et serpentibus atris/cum fugit ultricesque sedent in limine Dirae. (Verg. A. 4, 471-473).

${ }^{35}$ En La Divina Comedia de Dante, aparecen las'Epıvv́e a las puertas de la ciudad de Dite, que es el punto de entrada al sexto círculo inferior del Infierno.

${ }^{36}$...Quia licet id raro contingat, ut mater filio vel iuste irata, defuncto non ignoscat, contingere tamen potest: quia si verum fuit in Medea, quod Maro[=Verg. Ecl. 8, 47-48] in Bucol[icis] cecinit. Saevus amor docuit natorum. (Badius, 1528: xxxviii R).

${ }^{37}$ Saeuos Amor docuit natorum sanguine matrem/commaculare manus; crudelis tu quoque, mater (Verg. Ecl. 8, 48-47). Esta cita está inserta en el poema bucólico 8, en este pasaje los dos pastores Damón y Alfesibeo cantan su amor contrariado. Damón expresa la traición de su amada Nisa que se ha entregado a otro. Hace alusión a la lección moral que se desprende del mito de Medea, quien se dejó llevar por la ira y como consecuencia, este furor la condujo a un saevus amor por sus hijos.
} 
Medea en la tradición es representada como inestable, temible, vengativa y cruel; durante el medievo y el renacimiento hispánicos, la sacerdotisa de Hécate fue configurada como la autoridad nigromántica, un modelo ideal e imitable para los magos, las hadas y los sabios encantadores ${ }^{38}$.

\section{ANÁLISIS DE LOS EJEMPLOS PROPUESTOS Y SU CONTEXTUALIZA- CIÓN}

\subsection{Las novercae}

Se detiene el escoliasta en el odio que sienten las novercae contra sus hijastros, con motivo del ya mencionado texto de Quintiliano ${ }^{39}$. Puntualiza este lugar con un pasaje de la Bucólica 3, 33 y otro de las Geórgicas 3, 280-283². Colegimos que determinados sustantivos van asociados al campo semántico de la magia y de la ira, como es el caso del sustantivo noverca. Esta última, a lo largo de la latinidad, es tildada con adjetivos como saeva (Verg. G. 2, 128), mala (Verg. G. 3, 282) y seclerata (Ov. Fast. 3, 853). La Bucólica 3, 33 la designa como iniusta, la geórgica 3, 280-283 señala la costumbre de las novercae, ellas recogían el veneno llamado hipomanes que destila el útero de las yeguas en primavera, posteriormente, lo mezclaban con hierbas al ritmo de sus conjuros $^{41}$. Según Frances Yates el concepto renacentista del Mago es un paso crucial y necesario en la formación del pensamiento moderno. La figura del Mago refleja la "reorientación psicológica" de la voluntad hacia la acción, asegurando así la dignidad de las capacidades instrumentales del hombre ${ }^{42}$.

\footnotetext{
${ }^{38}$ En los libros de caballerías hispánicos del siglo XVI, la maga no solo fue un referente cultural heredado de la tradición grecolatina, sino que su presencia constituyó un rico y poderoso recurso narrativo, con posibilidades evocadoras de un pasado remoto, mágico, maravilloso y mítico.

${ }^{39}$ Véase nota 10.

${ }^{40}$ Eorum hic primus est a persumpto novercarum in privignos odio: unde Maro in Bucolicis communi utitur epitheto. Est mihi namque domi pater, est iniusta noverca. Et in Georgicis Hippomanes[=Verg. G. 3, 282-283] quod saepe malae legere novercae. Miscueruntque herbas et non innoxia verba: ubi etiam veneficii eas insimulat. (Badius Ascensius, 1528: fol. vi R).

${ }^{41}$ La madrastra, en la tradición popular y en la literatura, ha sido siempre considerada como malévola y como hechicera experta en venenos. Recordaremos a La Gata Cenicienta de Giambattista Basile (15751632) donde la heroína llamada Zezolla no solo sufre las vejaciones de una madrastra sino de dos. A la primera le da muerte aconsejada por su madrina. Ella, a su vez, se casa con su padre y la manda a vivir a la cocina y realizar todas la tareas domésticas. Cenicientas ha habido en muchas culturas, se puede hablar de proyección universal de este cuento. Ya en el siglo IX Taun Cheng-Shing, uno de los primeros folcloristas del mundo, la recoge. En esta versión se llama Yehshien, tiene una madrastra que le obliga a hacer las tareas más duras de la casa y va vestida con harapos. Ella sueña con fiestas y ropas lujosas por fin, consigue ir a un baile donde pierde un zapato. Un rico comerciante queda enamorado de ella, finalmente, ordena a sus criados que la busquen. En épocas posteriores aflorará el cuento de Blancanieves donde aparece la madrastra-bruja que baja a una cámara secreta y prepara una manzana con el veneno más virulento y el de Los dos hermanos, en la colección de Grimm, donde la madrastra había embrujado todas las fuentes del bosque.
}

42 (Yates, 1964: 156). Marsilio Ficino (1433-1499) anuncia entusiasmado la eficacia de los poderes humanos evidente en las prácticas de magia. El misticismo oriental, el naturalismo helénico, la sacralización egipcia del mundo orgánico, la alquimia y la magia dejaron una huella profunda en su visión de la 


\subsection{La mors voluntaria}

En la Declamatio ${ }^{43}$ 4, 21 el hijo deja claro que no va a ser el vaticinado parricida, exterioriza sus sentimientos buenos hacia su padre. Quiere evitar el augurio del matemático y por este motivo quiere suicidarse ${ }^{44}$. Hay que aclarar que era un ideal filosófico estoico. Séneca entendía el suicidio como una liberación, Lucano es el poeta del suicidio. Quintiliano ${ }^{45}$ se sirve en el praefatio de la fórmula mors uoluntaria ${ }^{46}$. Expone en la Declamatio (Quint. Decl. 4, 21) que el hijo prefiere quitarse la vida, ahora bien, los dioses no permiten que el último acontecimiento juzgue los hechos, precisamente, porque este acto requiere reflexión. Por otro lado, el escoliasta aclara el contenido de este pasaje ${ }^{47}$ con un dístico elegíaco de Ovidio: Exitus acta probat. Carear successibus opto,/Quisquis ab eventu facta notanda putat./(Ov. Ep. 2, 85-86).

En la Declamatio 5, 10 el orador ${ }^{48}$ riojano alude al lamento de un padre por el desamor de su hijo hacia él. Pues, no eligió salvar su vida, al contrario, auxilió a su otro hijo. No obstante, este hecho no demuestra que no quisiera a los dos. Argumenta como

naturaleza, que pese a la variedad de sus fuentes, es homogénea, original y global. (Kwiatkowska, 1997: 143-154).

${ }^{43}$ Praedico, testor: non ego parricidium faciam, non ego fortiter feci. Quod si ulla ratione casuve effici potest, ut praedicta non fiant, fidem vestram, P.C., ut mihi potius innocentia quam fato debeatur: ego dicar expugnasse constitutionem, fregisse vincula necessitatis, mea pietas, mea laudetur integritas. dii non sinant, ut inter me responsumque decernat exitus; mathematicum vincere malo quam reprehendere. Quid nunc agam. (Quint. Decl. $4,21)$.

${ }^{44} \mathrm{El}$ asesinato y el suicidio son dos acciones distintas para Quintiliano como para sus contemporáneos romanos. No pueden designarse con los mismos términos ni con componentes iguales; por ello, buscaron fórmulas y expresiones en las que no existían las connotaciones de agresividad, violencia y criminalidad. Así, lo expone en su Institutio: Diuersum est genus, cum controuersia consistit in nomine, quod pendet ex scripto, nec uersatur in iudiciis nisi propter uerba quae litem faciunt: an, qui se interficit, homicida sit;... Res enim manifesta est, sciturque non idem esse occidere se quod alium... (Quint. Inst. 7, 3, 7). La consideración del suicidio y del suicida como homicidio y homicida no se produce hasta Lactancio y Agustín de Hipona. (Hinojo, 2010: 57-72).

${ }^{45}$ Vir fortis optet praemium quod volet. Qui causas <voluntariae> mortis in senatu non reddiderit, insepultus abiciatur. Quidam de partu uxoris mathematicum consuluit. is respondit virum fortem futurum, qui nasceretur, deinde parricidam. cum adolevisset qui erat natus, bello patriae fortiter fecit. reddit causas voluntariae mortis. pater contradicit. (Quint. Praef. 4).

${ }^{46}$ Leemos mors prematura en la expresión: numquam sibi videbitur praematura morte periturus.(Quint. Decl. $4,9)$.

${ }^{47}$ Ego praedico et protestor, ego non faciam parricidium, sed furor et impetus fatorum per manus meas, qua ego non feci fortiter, sed eadem fatorum vis per me. Quod si potest effici, id est, caveri ulla ratione aut casu ut praedicta a mathematico tali non fiant: P.C. imploro et obtestor vestram fidem, ut innocentia debeatur potius mihi impediendo vim fati per mortem voluntariam: non debeatur fato, id est, mentito et non facienti quod minatur sit: ut supra ego dicar, id est, praedicer ad gloriam meam, expugnase, id est, vicisse constitutionem astrorum et fatorum, et fregisse vincula necessitatis, id est, fatalis, mea pietas, et mea integritas laudetur. Quaeras quomodo frangere speret necessitatem. Sed noris, quod supra dixit non esse necesse simpliciter nisi vixerit, at si vixerit innuit frangi non posse, quo argumento efficacissime mortem orat. Dii non sinant, ut exitus, id est, ultimus eventus (unde Sappho Ovidiana. Exitus acta probat, careat successibus opto Quisquis ab eventu facta notanda probat) discernat, id est diiudicet inter me et responsum, id est, mathematici, id est, utrum plus potuerit an pietas mea cavendo parricidio, an vis fati in purgendo. (Badius Ascensius, 1528: fol. xxviii R).

${ }^{48}$ Remove, iuvenis, indignationem; nihil plus pro filio factum est, quem recepi. non fortunam tibi debeo sed affectum, non exitum sed voluntatem. (Quint. Decl. 5, 10). 
defensa que, a la hora de actuar, se debe pensar más en la intención, la predisposición, la voluntas que en el resultado, el exitus. Ante esta reflexión de Quintiliano, el humanista ${ }^{49}$ ilustra este pasaje con el hexámetro de la Heroida II, $85^{50}$, ya manejado antes, para apostillar $^{51}$ el texto del rétor (Quint. Decl. 4, 21), igualmente, se lo atribuye a la poetisa de Lesbos. El hecho de que, en ambos textos, Ascensius le haya otorgado el mismo remitente puede ser por su similitud en el contenido. Filis y Safo son abandonadas cruelmente y por otro lado, se entregan al suicidio como una salida a su situación. Esta estrofa aducida como ejemplo por el humanista tuvo eco en la obra de Nicolás Maquiavelo (1469-1527) El Príncipe, publicada en Roma en 1513. Baltasar Gracián, en su tratado didáctico Oráculo manual y arte de prudencia de 1650, escribió: "Todo lo dora un buen fin, aunque lo desmientan los desaciertos de los medios".

\subsection{La predicción del futuro y los fenómenos de la naturaleza}

La Declamatio 4, 16 versa sobre las señales que preludian acontecimientos insólitos ${ }^{52}$. Al hilo de lo expuesto, es lícito recordar a Tales pues, otorga alma a todo el universo al creer que hay una vida oculta en todas cosas, la imagen viva del universo natural. Badius ${ }^{53}$ apostilla este pasaje desde la óptica renacentista en sus inicios: el

\footnotetext{
${ }^{49} \mathrm{O}$ iuvenis quod qui non mereris vocari filius: remove indignationem tuam in me a corde tuo: nihil plus factum est a me pro filio quem recepi, id est, redemi, quam pro te. Ego non debeo tibi fortunam, id est, praestare casum fortuitum in te malignum, sed affectum esse paternum: non exitum, id est, rei, id est, eventum, sed voluntatem: unde Sappho Ovidiana. exitus acta probat, careat successibus, op to Quisquis ab eventu facta notanda putat $[=\mathrm{Ov}$. Ep. 2, 85]. (Badius Ascensius, 1528: fol. xxxii R).

${ }^{50}$ Posteriormente, N. Heinsius (1620-1681) hará mención del hexámetro -ya aducido- en su edición a Ovidio. Argumenta que lo que aparentemente parece malo antes de llegar al fin, una vez acabado, puede resultar bueno. Describe que Filis quiere que el pueblo tracio la juzgue por la intención de favorecer a los suyos y a ella, contrayendo matrimonio con el hijo de Teseo. No quiere que se le censure por el resultado funesto de ser abandonada por el hombre que amaba. Exitus acta probat.] Per ironiam Thracum verba repetit, qui Phyllidis concilia a fine damnabant. Caveat successibus.] Purgat se a fortuna. Careat successibus, etc.] Sensus est, male illi eveniat, qui non a fine rerum, sed ab eventu facta hominum denominat, et notat. Multa enim solent evenire ante finem, quae videntur esse mala, quae postea ex fine cognoscunt esse bona. Hubertus Vander Meer i? -1712). Notanda.] Iudicanda, et probanda. Hubertus Vander Meer. Ab enentu.] A fine, quem ego respexi, et propter quem feci, nam finis mei facti fuit, prodesse mihi et meis, accipiendo te maritum: ergo ab hoc fine, intentionis meae, et non ab eo qui evenit, iudicandum est id quod feci Hubertus Vandeer Meer. (Heinsius, 1670: 23). Acerca de este mismo verso P. Burmann escribe en la misma línea: Exius acta probat.] Varia de hoc loco disputant. V.[ide] Salmas.[ius Claudius 1588-1653] [Observationes] ad Ius Att.[icum et Romanum Lugduni Batavorum 1645] P. 344. verus autem eius sensus hic est. Exitus acta probat, id est, bonus exitus facta probanda esse efficit, sed opto ut successu careat, quisquis facta culpanda esse credit post bonum exitum... (Burmann, 1727: 22).

${ }^{51}$ Véase nota 46.

${ }^{52}$ Necesse est et maiores notas ventura praemittant, quae non temere nascuntur. sic futuras tempestates pelagi fragor et conscium nemorum murmur enuntiat, sic periturorum fata populorum ardentes caelo faces et crinita siderum flamma praecurrit. (Quint. Decl. 4, 16).

${ }^{53}$ Necesse est ut ventura quae nascuntur non temere, id est, non sine magna causa, promittant, id est, ante se mittant, maiores notas, id est, manifestiora signa insolitorum eventorum. Sic fragor pelagi, et murmur nemorum, conscium, id est, praesagum, enunciat tempestates futuras, et alia mala, ut Geor. i. Vox quoque per lucos vulgo exaudita silentes [=Verg. G. 1, 476]. At de tempestate in eadem ante ingeminant austri et densissimus imber. Tunc nemora ingenti uento, nunc litora plangunt $[=$ Verg. G. 1, 333-334]. Et iterum Et nemorum increbrescere murmur[=Verg. G. 1, 359]. Sic faces ardentes caelo et flamma siderum crinita, id est, cometa praecurrrit fata
} 
fluir de la vida en las cosas sin que exista un método para distinguir lo inanimado de lo animado. Brinda varios fragmentos de Virgilio de las Geórgicas donde aparece gimiendo la fronda y la costa (Verg. G. 1, 333-334), el murmullo del arbolado (Verg. G. 1, 359) y el silencio de los bosques (Verg. G. 1, 476). Enumera los prodigios posteriores a la muerte de César (Verg. G. 1, 466-488). La imagen de la naturaleza anárquica ha desempeñado un papel importante en la temprana Edad Moderna.

Nicolás Maquiavelo (1469-1527) compara a la sociedad y a la fortuna con la naturaleza salvaje, violenta e imprevisible. Esta cuestión se vislumbra en La Tempestad de W. Shakespeare. El dramaturgo contrasta las fuerzas salvajes de la naturaleza con la tranquilidad de la vida creada por el ingenio humano.

\section{LAS APORTACIONES DE UN RENOVADO GRAMÁTICO}

Es uno de los aspectos que debe plasmarse en su función de instruir a sus futuros lectores. Mi objetivo es hacer ver su preocupación y cuidado acerca de la utilización de la lengua latina. Karl Enenkel y Henk Nellen estiman que el comentarista pone un gran énfasis en transmitir los conocimientos e ideas ${ }^{54}$. Sin embargo, aflora su cuidado en la creación literaria a través de los comentarios que vamos a analizar. Detallaremos su predilección en ahondar en los diferentes matices que un empleo lingüístico puede tener.

\subsection{El uso de los superlativos}

El texto comentado es: debet proxima pars a cubiculo patris habere plurimum sanguinis, sequens minimum, ultima nihil. (Quint. Decl. 1, 11). Nuestro gramático apunta ${ }^{55}$ el empleo non recte de los superlativos como minus elegans. A tenor de lo visto, hay quienes piensan que Quintiliano ${ }^{56}$ no es su autor; por el contrario, Valla (1407-1457) reconoce la autoría de su trabajo, pensamiento que refleja en sus Elegantiae Linguae Latinae o en las notas a la Institutio Oratoriae ${ }^{57}$. En el primero de sus mencionados trabajos, se aclara que el superlativo es la máxima expresión de la gradación ${ }^{58}$.

Badius corrige este lugar con la fórmula: sequens minus, tertia minimum, ultima nihil.

populorum periturorum: unde Maro de caede Iulii Caesaris et male eam secuturis Georg., id est, Non alias caelo ceciderunt plura sereno Fulgura: nec diri toties arsere cometae[= Verg. G. 1, 487-488]. (Badius Ascensius, 1528: fol. xxvii A).

\footnotetext{
${ }^{54}$ (Enenkel y Nellen, 2013: 1-76).

${ }^{55}$ Non recte utitur superlativis...unde propter has et alias multas locutiones minus elegantes. (Badius Ascensius, 1528: fol. vi A).

${ }^{56}$ Unde propter has et alias multas locutiones minus elegantes, sunt qui negent has declamationes esse eius Quintiliani cuius sunt libri de institutione oratoria. Quia tamen Valla eas Quintiliani citat, nec taxat hunc locum, putem eum mancum, et in Vallensi codice integrum, ut sexcentos locos integros ostendimus in Vallensi de oratoria exemplari. (Badius Ascensius, 1528: fol. vi A).

${ }^{57}$ (Fernández López, 1993: 181-188).

${ }^{58}$ Necesse enim est ubi superlatio est, ibi sit et comparatio, ut aliquod sit maius aliquo, et item alterum maius hoc, quod erit iam omnium maximum. (López Moreda, 1999: 106).
} 
Sánchez de las Brozas (1523-1600) en su gramática latina denominada Minerva se opone a esta propuesta ${ }^{59}$.

\subsection{La expresión tuitus sum}

La forma tuitus sum (Quint. Decl. 1, 13) se aplica para marcar la transición de la defensa del muchacho ciego a la argumentación de la madrastra. El intérprete diserta ${ }^{60}$ acerca de la doble lectura: tutus frente a tuitus. Aclara que ambas voces proceden del mismo verbo tueor, sin embargo, el primero tiene significado pasivo y el segundo activo, a tenor de lo expuesto, opta por tuitus sum con la acepción de defendi.

\subsection{El giro monstri mei}

Respecto a esta expresión ${ }^{61}$ (Quint. Decl.4,16) el gramático ${ }^{62}$ alude a Valla ${ }^{63}$ para justificar la conveniencia de meum o de mei. El humanista italiano en sus Elegantiae Linguae Latinae trata de la diferencia entre el uso de los pronombres mei, tui y sui y sus derivados meus, tuus y suus. En el primer caso se entienden como pasivos y en el segundo como activos e indican posesión.

Badius considera que se debe optar por meum en tal caso, interpreta que "él es un monstruo, un esperpento de hombre". Valla se decanta por mei con la acepción de "en aquel día del nacimiento de mi monstruosa vida", es decir, "padezco una existencia horrible".

\footnotetext{
${ }^{59}$ Si superlatum significaret ultimum excessum, quod grammatici asserunt, non haberet numerum pluralem, quia unus semper in eodem genere tantum deberet excellere...At si dicas haec eadem ratio erit in comparatis nominibus, nihil ages: omnes enim concedunt in comparativis excessum esse, sed non ultimum excessum, quod de superlativis grammatici asserunt... (Sánchez Salor, Chaparro Gómez, 1995: 192).

${ }^{60}$ Sicque dicitur tuitum et tutum, sed tuitum etiam a tueor: et significat active, tutus autem passive nisi ob sequelam...Ordo itaque est. Tuitus sum, id est, denfendi hactenus o iudices causam adolescentis miserrimi, id est, misericordia dignissimi, quia innocentissimi: et iniustissime accusati. (Badius Ascensius, 1528: fol. vi R.)

${ }^{61}$ Credo mehercules in illum natalem monstri mei diem iratorum numinum conspirasse violentiam sedemque prodigiosi spiritus conlato pariter igne pressisse. (Quint. Decl. 4, 16).

${ }^{62}$ Mehercule, ego credo violentiam numinum iratorum conspirasse in illum diem natalem, monstri mei, id est, monstruosae vitae meae: aut (quod valla recte dici neget, in illum natalem mei, per meum, monstri, id est, quod sum monstrum in natura natus, ad ea quam ratio non compatitur, qua sententia quam mihi placet, legam meum ut sit in illud natalem meum, monstri, id est, quod ego sum monstrum quoddam. (Badius Ascensius, 1528: fol. xxvi R).

${ }^{63}$ Primum est, causa mea venisti, et causa mea; causa mea accipitur possesive, eo modo quo via mea venisti, pecunia mea fecisti sumptum, iter meo sumptu fecisti. Causa mei vero passive, eo modo quo benevolentia mei. Modus tamen prior est usitator. (López Moreda, 1999: 192).
} 


\subsection{Referencias léxicas}

En el capítulo siguiente de la estudiada práctica declamatoria ${ }^{64}$, aduce un pentámetro dactílico del elegíaco Ovidio ${ }^{65}$ (Ov. Fast. 1, 596) cuando elucida cuestiones acerca del vocablo notabilis (Quint. Decl. 4, 17) y de sus sinónimos: nobilis, insignis, egregius y singularis para indicar cosas buenas como malas, así como la forma notus-aum.

\subsection{Usos elegantes}

El erudito ${ }^{66}$ puntualiza dos aspectos respecto a la proposición: non sustineo eosdem expetere convictus, ne, quos porrexerim cibos, venena fiant. (Quint. Decl. 4, 19). En primer lugar, considera que el perfecto del modo subjuntivo debe ser sustituido por el futuro perfecto. A partir de Plauto hay una total equiparación entre el futuro perfecto y el subjuntivo de perfecto, aun cuando subsistía la diferencia de la primera persona del singular ${ }^{67}$. El contexto nos orienta en algunos casos, en otros es muy difícil saber la diferencia. En segundo lugar, quiere remarcar el uso elegans del relativo entrecruzado quos...cibos. Especifica que se ha de analizar como si se dijera: ne cibi quos porrexerim, venena fiant. Añade que Valla ya lo había marcado. Este aspecto lo encontramos en su libro tercero, capítulo dieciocho en su obra De linguae Latinae Elegantia libri sex ${ }^{68}$.

\subsection{El participio indulgens}

El rétor hispanorromano ofrece esta forma (Quint. Decl. 5, 8) asociada a facilis y mitis para exteriorizar los sentimientos que puede tener un amigo e incluso un extraño hacia una persona que necesita ayuda. El lingüista ${ }^{69}$ e impresor belga aclara que indulgens es equiparable a obsequens: "el que mira por otros, no por el que otros miran", esto es, le da valor activo a la forma nominal del verbo. Así pues, contradice la

\footnotetext{
${ }^{64}$ Quid enim aliud fecit me notabilem, id est, insignem in bello (Est autem meson vocabulum, ut nobilis, insignis, egregius, singularis, sed haec saepius in bonum, illud in malum capitur sicut et nota, quae tamen interdum bona est. Ovidius Ille numantina traxit ab urbe notam). (Badius Ascensius, 1528: fol. xxvii A).

65 ille Numantina traxit ab urbe notam. (Ov. Fast. 1, 596).

${ }^{66}$ Non sustineo, id est, non sum prae timore potens et non audeo expetere eosdem convictus quos tu, id est, tecum eosdem sumere cibos, ne quos cibos porrexerim per porrexero, fiant venena: elegans locutio et a Valla signata per ea qua citra elegantiam dicas: ne cibi quos etc. (Badius Ascensius, 1528: fol. xxviii A).

${ }^{67}$ (Schütz, 1920: 161-162), (Thomas, 1938: 170), (Bassols, 1948: 330-332).

${ }^{68}$ Oratores autem postponunt antecedens, quale foret, quam urbem statuo, vestra est, ut apud Ovidium: Cecidere manu, quas legerat herbas. Et quale Quintilianus: Timeo ne quos porrexerim cibos, venena fiant.. In quo est habita ratio venustatis, ut relativum et antecedens sint in eodem casu. (López Moreda, 1999: 328-330).

${ }^{69}$ 'Facilis, mitis, indulgens' vocabula sunt ista minoris affectus; propter haec aleretur amicus, pasceretur extraneus. (Quint. Decl. 5, 8). Facilis, mitis, indulgens, id est, obsequens et quod plus aequo indulget (ubi signandum est quod indulgens active capitur per eo quod indulget, non per eo cui indulgetur, quod tacuit Valla) ista, id est, tria dicta, sunt vocabula affectus minoris, quo minus devinciuntur inter se homines, quod filii erga parentes: et tamen amicus aleretur, id est, extraneus pasceretur propter haec, id est, si sit facilis, mitis et indulgens. (Badius Ascensius, 1528: fol. xxxi R).
} 
aportación de Valla ${ }^{70}$ recogida en el libro primero capítulo treinta y dos en la citada obra. Este erudito italiano alecciona acerca del participio de pretérito que significa "acción" y del presente que significa "pasión". Sin embargo, respecto a esta última categoría, reconoce que son menos los casos de participios de presente con valor pasivo. Pone el ejemplo de esta locución: indulgentior facies y la asemeja a pulchra facies, entendible no como "la que mira por otros", sino "por la que otros miran".

\section{CONCLUSIONES}

La lengua es un vehículo de las actividades culturales, así, se ha puesto de manifiesto a lo largo del comentario tanto de Quintiliano como de la paráfrasis de nuestro escoliasta. Los escolios de Badius atienden a diferentes aspectos: realiza aclaraciones acerca del contenido, utiliza, como recurso, los ejemplos de otros autores; también aborda en sus glosas cuestiones léxicas, gramaticales y referentes a la crítica textual. Las recreaciones mitológicas muestran al hombre como centro del universo con sus virtudes y sus defectos, tratan de temas que son universales y presentes en el folclore.

Los ejemplos que utiliza el humanista están extraídos en gran parte de Virgilio y Ovidio, además, son muy apropiados a la cosmovisión renacentista. La naturaleza está en sus versos y aparecen elementos mágicos en algunos de ellos. Finalmente, en su labor de gramático hace correcciones al texto, no sin tener en cuenta a Valla al que cita en sus notas.

Las aportaciones pertenecen tanto al plano de la morfología nominal y verbal como al sintáctico. El orador hispanorromano deja patente en sus ejercicios declamatorios los principios que propone en su Institutio Oratoria XII, 171. A lo largo de estas prácticas, se deja entrever la intención de moralizar y enseñar la mejor manera de actuar, sopesando las conductas humanas.

Badius también profundiza en las actuaciones del ser humano con intención didáctica. Los escritos de ambos autores están destinados a un lector atemporal, debido a la actualidad de las situaciones que plantea.

Sin embargo, dependiendo del contexto histórico donde se formulen estas creaciones aportan una serie de connotaciones que enriquecen todavía más el saber que transmiten. Poseen la virtud de no ser palabras gastadas y vacías de contenido.

\footnotetext{
${ }^{70}$ Et haec quidem significationis activae in voce pasiva; pauciora sunt in activa passivae. Evidens negotium dicitur, quod videtur aperte et intelligitur; non qui videt et intelligit. Indulgentior facies apud Quintilianum pro pulcra, non quae aliis indulgeat, sed cui alii indulgeat. Idem in alio loco: Fili, indulgentissime vidi te, nec semel vidi. (López Moreda, 1999: 176).

${ }^{71}$ Sit ergo nobis orator quem constituimus is qui a M. Catone finitur vir bonus dicendi peritus, verum, id quod et ille posuit prius et ipsa natura potius ac maius est, utique vir bonus: id non eo tantum quod, si vis illa dicendi malitiam instruxerit, nihil sit publicis privatisque rebus perniciosius eloquentia, nosque ipsi, qui pro virili parte conferre aliquid ad facultatem dicendi conati sumus, pessime mereamur de rebus humanis si latroni comparamus haec arma, non militi. (Quint. Inst. 12, 1).
} 
Ambos escritores tienen la capacidad de modelar y sugerir situaciones e incluso emociones. Abren una puerta en el tiempo y nos invitan a recrearnos e instruirnos en su jardín del saber.

\section{BIBLIOGRAFÍA}

Aguirre M. (2006): "Fantasmas trágicos: algunas observaciones sobre su papel, aparición en escena e iconografía", CFC (G), 16, 107-120.

Albrecht M. von (1999): Historia de La Literatura Romana II, Barcelona, Herder 2 vol: 1146.

Badius Ascensius J. (1528): Commentarii familiares Io. Badii Ascensii in M. Fabii Quintiliani declamationes: nuper editi, Parisiis, apud J. Badium Ascensium.

Bassols M. (1948): Sintaxis Histórica de La Lengua Latina, Barcelona, Consejo Superior de Investigaciones Científicas: 330-332.

Bornecque S. F. (1902): Les Declamations et les Déclamateurs d'après Séneque le père, Lille, Bibl. Univ. Lille.

Burmann P. (1727): Publii Ovidii Nasonis opera omnia Libri IV, Amstelaedami, apud R. \& J. Wetstenios, \& G. Smith 1 vol: 22.

Cousin J. (1967): Études sur Quintilien I, Amsterdam, P. Schippers 2 vol: 172-173.

Chomarat J. (1981): Grammaire et rhétorique chez Erasme, Paris, Belles Lettres: 281-299.

Cristóbal V. (1999): “El episodio de Polidoro en la Eneida (III19-68): variantes mitográficas, paralelos folclóricos y muestras de su pervivencia literaria", CFC (L), 16, 27-44.

Deratani N. (1929): “Le réalisme dans les déclamations”, REL, 50,184-189.

Enenkel K. and Nellen H. (2013): “The Commentary as an Educational Tool at Schools and Universities"(Introduction), in: K. Enenkel and H. Nellen (eds.) (2013) NeoLatin Commentaries and the Management of Knowledge in the Late Middle Ages and the Early Modern Period (1400-1700), Supplementa Humanistica Lovaniensia, 33, Leuven, Leuven University Press: 17-18.

Felice De P. (2001): “Pseudo-Quintiliano Declamazioni Maggiori 16, 1”, Invigilata lucernis, $23,53-54$.

Fernández López J. (1993): “Las anotaciones de Lorenzo Valla a la Institutio Oratoria de Quintiliano, relaciones con el resto de sus obras", CFC (L), 5, 181-188.

Fernández López J. (1999): “<<Quintilianus potior Cicerone?>>: una discusión humanista", en A. Aldama Roy et alii (eds.) (1999), La filología latina hoy: actualización y perspectivas I, Madrid, Actas del II Congreso de la SElat 2 vol: 913-924.

Garroso J. L. (2010): “Lisabetta y el tiesto de albahaca (Decamerón IV, 5): el sustrato folclórico de Boccaccio", CFI, Volumen Extraordinario, 163-177. 
Genette G. (1970): “Fronteras del relato” en R. Barthes et alii (eds.), Análisis estructural del relato, Buenos Aires, Tiempo Contemporáneo: 193-208.

González Vega F. (2003), “Para una tipología del lector en el comentario de Jocodo Badius Ascensio (Silvae Morales, 1492)", RELat, 3, 155-167.

Heinsius N. (1670): P. Ovidii Nasonis, Operum, Tom. I. Epist. Heroidum. De Arte Amandi, Lugduni Batavarum, Ex oficina Hakiana 3 vol: 23

Helm R. (1955): “Observatiunculae ad Ps.-Quintiliani Declamationes pertinentes”, en P. Jonge - E. J. Jonkers - H. M. Mulder et alii (eds.) (1955), Ut Pictura Poesis, Studia Latina Petro Iohanni Enk septuagenario oblata, Leiden, Brill: 87-98.

Hernán- Pérez M. P. (2009): “Darío, Clitemestra y Polidoro, personajes fantasma de la tragedia griega con algo que decir", Fortonatae, 20, 31-47.

Herrero J., C. y M. Morales Peco (2008): Reescrituras de los mitos. Estudios de mitocrítica y de literatura comparada, Cuenca, Ediciones de La Universidad de Castilla-La Mancha: 156-157.

Hinojo G. (2010): “Las Designaciones de la muerte voluntaria en Roma”, Hápax, 3, 5772.

Hömke N. (2002): Gesetzt den Fall, ein Geist erscheint, Komposition und Motivik der ps-quintilianischen Declamationes Maiores X, XIV und XV, Heidelberg, Universitätsverlag Winter Heidelberg.

Ingberg P. (ed.) (2004): W. Shakespeare. Tito Andrónico, Buenos Aires, Losada.

Jones F. (1998): “Notes on Quintilian and [Pseudo] Quintilian”, CQ, 38, 568-569. Kennedy G. (1972): The art of Rhetoric in the Roman World 300 b.C-a.C300, Princeton, Princeton University Press: 321-322.

Kwiatkowska T. (1997): “La naturaleza en el Renacimiento y la visione de Giordano Bruno", Iztapalapa, 41, 143-154.

Lemaire N. E. (1825): M. F. Quintilianus et Calpurnius Flaccus, de quorum operibus iudicia testimoniaque omnia, item Annales Quintilianos, editiones recensuit, et tres indices absolutissimos/emendavit, auxit VII, Parisiis, colligebat N. E. Lemaire 7 vol.

López Moreda S. (ed.) (1999): Laurentii Vallensis De Linguae Latinae Elegantia (1471) I, Extremadura, Universidad de Extremadura 2 vol.

Merino L. (1992): La pedagogía en la Retórica del Brocense, Cáceres, Institución Cultural «El Brocense», Excma. Diputación Provincial de Cáceres y Servicio de Publicaciones de la Universidad de Extremadura: 82-185.

Propp U. (1998): Morfología del cuento, Madrid, Akal.

Renouard P. (1908): Bibliographie des impressions des oevres de Josse Badius Ascensius, impreur et humaniste, 1462-1535 I, New York, B. Franklin 3 vol.

Robles Ma A. (2009) “El léxico en la Declamatio I, atribuída a Quintiliano, a la luz de la Institutio VIII y XII" I, en T. Arcos et alii (eds.) (2009), Pectora Mulcet: Estudios de 
Retórica y Oratoria Latinas, Logroño, Instituto de Estudios Riojanos 2 vol: 217230.

Robles Ma A. (2014): “Análisis del comentario de Badius Ascensius a la Declamatio I atribuida a Quintiliano" I, en J. M. Maestre et alii (eds.), Cádiz-Málaga, Instituto de Estudios Humanísticos 2 vol: 1207-1220.

Sánchez Salor E. y Chaparro Gómez C. (eds.) (1995): Francisco Sánchez de las Brozas. Minerva o De causis Liguae Latinae, Cáceres, Institución Cultural<<El Brocense>>, Universidad de Extremadura.

Saussure F. (1945): Curso de lingüística general, Buenos Aires, Losada.

Schütz H. (1920): “Die Konjunktiv und Futur formen auf “-ero-“erim” in Lateneischen, GL, 17, 161-162.

Stramaglia A. (1999): Res inauditae, incredulae. Storia di fantasmi nel mondo greco-latino, Bari, Levante: 9-10.

Thomas F. (1938): Recherches sur subjonctif latin, Paris, Klincksieck.

Tola E. (2010): “El texto y sus fronteras: cuerpo, ritual y poética trágica en el Tiestes de Séneca", CFC (L), 30, 117-130.

Weische A. (1978): “Zur Bedeutung der römischen Rhetorik”, en K. Büchner (ed.) (1978) Latein und Europa.Traditionen und Renaissence, Stuttgart, Reclam: 147-166.

White P. (2013): Jodocus Badius Ascensius: commentary, commerce and Print in the renaissance, Oxford, Oxford University Press.

Winterbottom M. (1984): The Minor Declamations Ascribed to Quintilian, Berlin, Walter de Gruyer.

Yates F. A. (1964): Giordano Bruno and the Hermetic Tradition, London, Routledge and Kegan Paul. 